\title{
Anatomical and Histological Study of the Effect of Lead on Hepatocytes of Albino Rats
}

\author{
El Sayed Aly Mohamed Metwally ${ }^{1}$, Fathia Ahmed Negm ${ }^{1}$, Rania Ali Shams El-din ${ }^{1}$, \\ Eman Mohammed Nabil ${ }^{2}$ \\ ${ }^{1}$ Department of Anatomy and Embryology, Faculty of Medicine, Alexandria University, Alexandria, Egypt \\ ${ }^{2}$ Department of Histology and Cell Biology, Faculty of Medicine, Alexandria University, Alexandria, Egypt
}

\section{Email address:}

sayedmetwally2020@yahoo.com (E. S. A. M. Metwally), fathianegm20002003@yahoo.com (F. A. Negm), sunshine19862002@yahoo.com (R. A. S. El-din), emannabil4@gmail.com (E. M. Nabil)

\section{To cite this article:}

El Sayed Aly Mohamed Metwally, Fathia Ahmed Negm, Rania Ali Shams El-din, Eman Mohammed Nabil. Anatomical and Histological Study of the Effect of Lead on Hepatocytes of Albino Rats. International Journal of Biomedical Materials Research.

Vol. 3, No. 4, 2015, pp. 34-45. doi: 10.11648/j.ijbmr.20150304.11

\begin{abstract}
Lead is found at low levels in Earth's crust, mainly as lead sulfide. Lead is toxic for virtually all organs of the body and has significant debilitating effects on the nervous, renal, hepatic and hematopoietic systems. The liver is considered as one of the target organs affected by lead toxicity owing to its site of storage after exposure. Also, the liver is being one of the major organs involved in the biotransformation and detoxification of toxic substances. Absorbed lead is stored in soft tissues mainly in the liver via the portal vein, so that it is the first organ for which the histological analysis can be used to examine the morphological changes that reflect possible lead effects on somatic cells. The present study aimed to determine the structural damage in the liver by histological study and biochemical assay of liver enzyme levels. 45 rats were divided into 3 groups. Group I (control group) included 15 rats that were given distilled water by orogastric tube. Group II (experimental group) included 15 rats that were given lead acetate in a dose of $4 \mathrm{mg} / \mathrm{kg}$ body weight by orogastric tube for two weeks. Group III (experimental group) included 15 rats given lead acetate by the same route and dose for four weeks. Significant increase of liver enzymes SGPT and SGOT was observed in experimental groups (group II and III). Administration of lead acetate for 2 weeks (group II) induced alteration in the hepatic architecture as evident by some of the hepatocytes appeared with acidophilic slightly vacuolated granular cytoplasm while others showed markedly vacuolated hypereosinophilic cytoplasm, Mononuclear cellular infiltration was seen in the portal tract. While in Group III, diffuse affection of the hepatic lobule was evident by extensive vacuolation of the hepatocyte cytoplasm, dark and eccentric nuclei. Others showed kayolytic nucleus, congested central vein, narrow or even obliterated blood sinusoids. The portal area revealed proliferation of bile ducts and congestion of its vessels. The hepatic architecture was disorganized with marked affection of the hepatocytes. In conclusion it was found that lead acetate is toxic to liver and this toxicity is paralleled with increased duration of exposure.
\end{abstract}

Keywords: Lead Acetate, Hepatocytes, Hepatic Fibrosis, Hepatic Architecture, Albino Rats

\section{Introduction}

The liver is the largest gland in the body. It is located in the upper three regions in the abdomen (Gartner and Hiatt, 2007). Hepatocytes are arranged in hexagon-shaped lobules (classical lobules) about $2 \mathrm{~mm}$ in length and $700 \mu \mathrm{m}$ in diameter. These lobules are clearly demarcated by slender connective tissue elements (known as portal tracts) in animals such as the pig and the camel. However, because of the scarcity of connective tissue and the closely packed arrangement of the lobules in humans, the boundaries of the classical lobules can only be approximated (Stevens and Lowe, 2004; Young et al., 2006; Williams \& Wilkins, 2008; Ross and Pawlina, 2010; Ovalle and Nahirney, 2013; and Bahl et al., 2014). Hepatocytes are involved in degradation of drugs, toxins, and other proteins foreign to the body (xenobiotics). Many drugs and toxins are not hydrophilic; therefore, they cannot be eliminated effectively from the circulation by the kidneys. The liver converts these substances into more soluble forms (Tso and McGill 2005).

Lead is found at low levels in Earth's crust, mainly as lead sulfide. However, the widespread occurrence of lead in the 
environment is largely the result of human activity, such as mining, smelting, etc (IARC, 2006). As lead is an element, once it is released into the environment, it persists. Because of lead's persistence and potential for global atmospheric transport, atmospheric emissions affect even the most remote regions of the world (Hernberg, 2000). Lead is toxic for virtually all organs of the body and has significant debilitating effects on the nervous, renal, hepatic and hematopoietic systems (Verity, 1990; Landrigan, 2002; Siposet al., 2003; and Patrick, 2006)

Inhalation and ingestion are the two most common routes of entry of lead into the body. Although ingestion is more common source, inhalation is the most significant as pulmonary absorption is efficient. Lead is absorbed in the blood plasma where it equilibrates with the extracellular fluid, crosses membranes such as the blood brain barrier and placenta, and accumulates in soft tissues and bones. Lead that is stored in bones can have a half-life of up to 28 years and can be mobilized intermittently at times of stress, lactation or hormonal imbalances (Needleman, 2004; Pearce, 2007). Gastrointestinal ingestion is the most common source of lead intake in the body as lead does not have a feedback mechanism to inhibit its uptake (Patrick, 2006).

Lead is used mainly in the production of lead-acid batteries, plumbing materials and alloys. Other uses are in cable sheathing, paints, glazes and ammunition. Human occupational exposure can also take place during the application and removal of protective lead-containing paints, during the grinding, welding and cutting of materials painted with lead-containing paints, such as in ship building, construction, demolition industries, and fabrication of heavy lead glass and crystal, and in crystal carving. Mining, smelting, and informal processing and recycling of electric and electronic waste can also be significant sources of exposure. The use of leaded petrol (gasoline) is another significant source of exposure (Patrick, 2006; Xu et al., 2009).

Absorbed lead is stored in soft tissues mainly in the liver via the portal vein, so that it is the first organ for which the histological analysis can be used to examine the morphological changes that reflect possible lead effects on somatic cells.

The present study was designed to explore the toxic effects of lead acetate on hepatocytes in albino rats.

\section{Material \& Methods}

Forty five healthy adult albino rats of 3 months age 150$200 \mathrm{gm}$ were acclimated for a week. The animal procedures were performed in accordance with Guidelines for Ethical Conduct in the Care and Use of Animals, maintained at room temperature of $25 \pm 2{ }^{\circ} \mathrm{C}$ with 12-hour dark-light cycle. Animals were fed with standard rodent diet. There was no water and light restriction throughout the experimental period. They were divided into 3 groups:-

Group I (Control group): included fifteen rats that were given distilled water by orogastric tube.
Group II (experimental group): included fifteen rats that were given lead acetate in a dose of $4 \mathrm{mg} / \mathrm{kg}$ body weight by orogastric tube for two weeks.

Group III (experimental group): included fifteen rats that were given lead acetate by the same route and dose for four weeks.

This dose was prepared by dissolving $0.6 \mathrm{mg}$ of lead acetate trihydrate into $1000 \mathrm{ml}$ of distilled water according to (Jin, et al. 2008)

After two and four weeks of exposure the following was done:

\section{I- Biochemical examination of liver function:}

After 2weeks (group II) and 4 weeks (group I and III), blood samples were collected in sterilized dry centrifuge tubes. Blood was collected from the tail vein. The rat-tail was immersed in warm water $\left(40^{\circ} \mathrm{C}\right)$ for 2 minutes. The tip of the tail was cut using a new scalpel blade. Blood was collected by gently squeezing the tail. Blood samples were allowed to clot for 30-40 min at room temperature. Centrifugation was done at $2500 \mathrm{rpm}$ for $15 \mathrm{~min}$, serum was separated and biochemical parameters of serum glutamic oxaloacetic transaminase (SGOT) and serum glutamic pyruvate transaminase (SGPT) were estimated by using ELISA (Enzyme Linked Immunosorbant Assay) technique at the Clinical Pathology department (Siest and Schielef, 1981; Arneson and Brickell, 2007).

\section{II- Histological study:}

After the sacrifice of rats the right liver lobes from all animals were excised and cut into 2 specimens. The specimens were subjected to light and electron microscopic studies:

1. The first specimen was immediately removed after sacrification and immediately fixed in 3\% phosphate buffered glutaralehyde ( $\mathrm{Ph} \mathrm{7.4)}$ for 2 hours at $4^{\circ} \mathrm{C}$, and further processed for examination and photography of the ultrastructure by Joel -100 CX transmission electron microscope, Faculty of Science, Alexandria University (Glauret, 1986; Bozzola and Russell, 1992 and Trevor and Graham, 1996).

2. The second specimen was fixed in $10 \%$ formal saline and processed to get $5 \mu \mathrm{m}$ thick paraffin sections. These sections were stained with Haematoxylin \& Eosin stain for routine histological examination (Carletons et al., 1980).

\section{Results}

During the experiment all rats were carefully monitored for behavior, appearance, palpable tumors, and infections. No mortality was detected in all groups during the study period ( 2 and 4 weeks). There was no rejection of the diet in both control and experimental groups. The hair of the rats of control group (group I) was healthy while in group II and III the hair was brittle, pale and scarce. The body weight of the control group was $195 \pm 10$ gram ranging from 185 to 205 after 2 weeks and $205 \pm 10$ after 4 weeks while group II the body weight was $177 \pm 8$ gram ranging from 171 to 181 . In group 
III the body weight was $169 \pm 7$ ranging from $168-172$. The weight of liver was significantly increased in group II and III as compared with control group.

I- Biochemical results:

Serum SGOT and SGPT

Table I. SGOT and SGPT values of control and experimental rats.

\begin{tabular}{lll}
\hline Groups & SGOT & SGPT \\
\hline Group I (Control) & $49.8^{\mathrm{bc}} \pm 1.79$ & $53.2^{\mathrm{c}} \pm 4.3$ \\
Group II (Experimental group) & $279.8^{\mathrm{ac}} \pm 25.38$ & $57.8 \pm 11.56$ \\
Group III(Experimental group) & $363^{\mathrm{ab}} \pm 117.1$ & $61.4^{\mathrm{a}} \pm 11.37$ \\
F(p) & $82.479^{*}\left(<0.001^{*}\right)$ & $2.701(0.079)$ \\
LSD & 50.77 & 7.10 \\
\hline
\end{tabular}

Data are expressed (15 rats in each group) as Mean \pm SD a: Significant with control group b:Significant with group II Experimental group

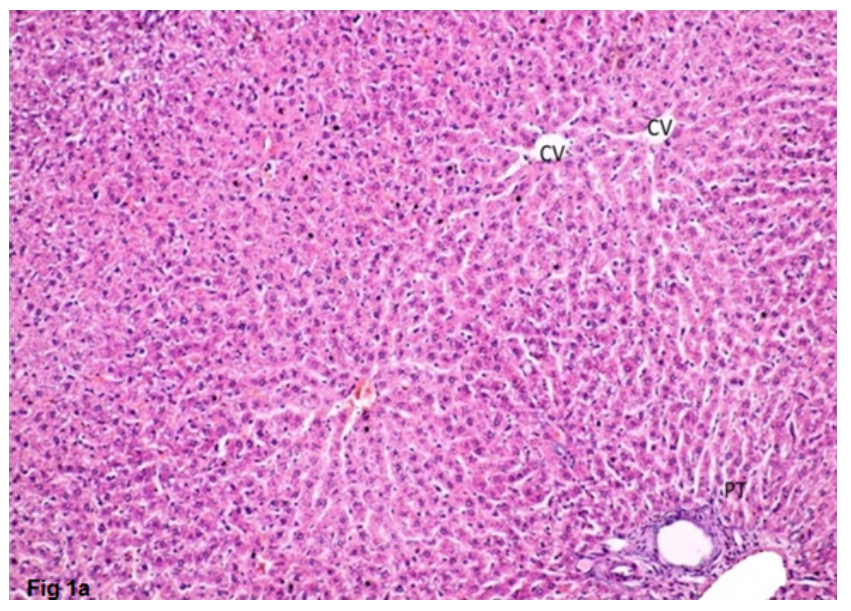

c: Significant with group III Experimental group

*: Statistically significant at $\mathrm{p} \leq 0.05$

Rats exposed to lead acetate showed a significant increase in Serum SGOT and SGPT concentrations as compared with the control group, the level of SGOT was increased more significantly than SGPT (table I).

Statistical analysis of the data:

Data were fed to the computer and analyzed using IBM SPSS software package version 20.0. The values of SGOT and SGPT in the groups were presented as mean and standard deviation. The data were analyzed using one way analysis of variance (ANOVA) followed by least significant difference (LSD) analysis to compare various groups with each other. Values of $p>0.05$ were considered non significantly different, while those of $p<0.05$ and $p<0.01$ were significantly and highly significantly different respectively. (PC - STAT; 1995)

II- Light Microscopic Results:

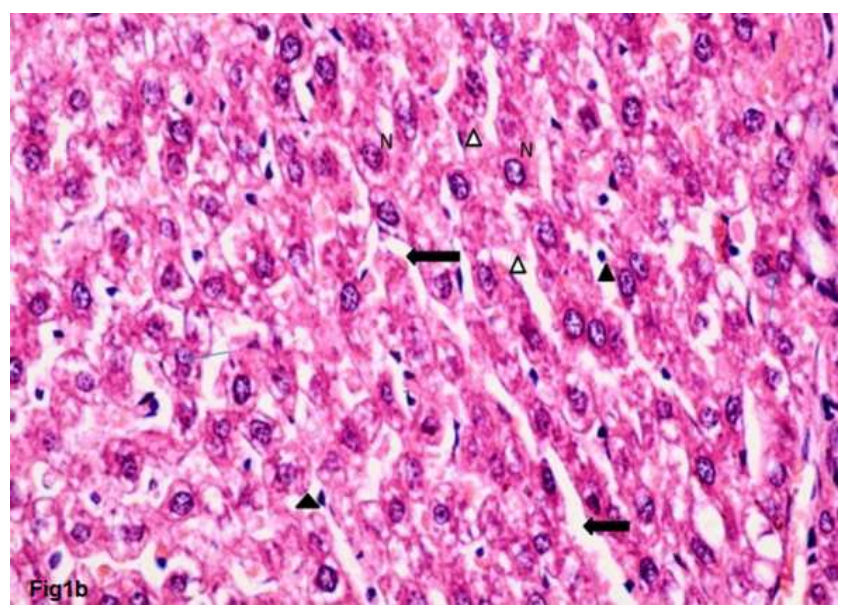

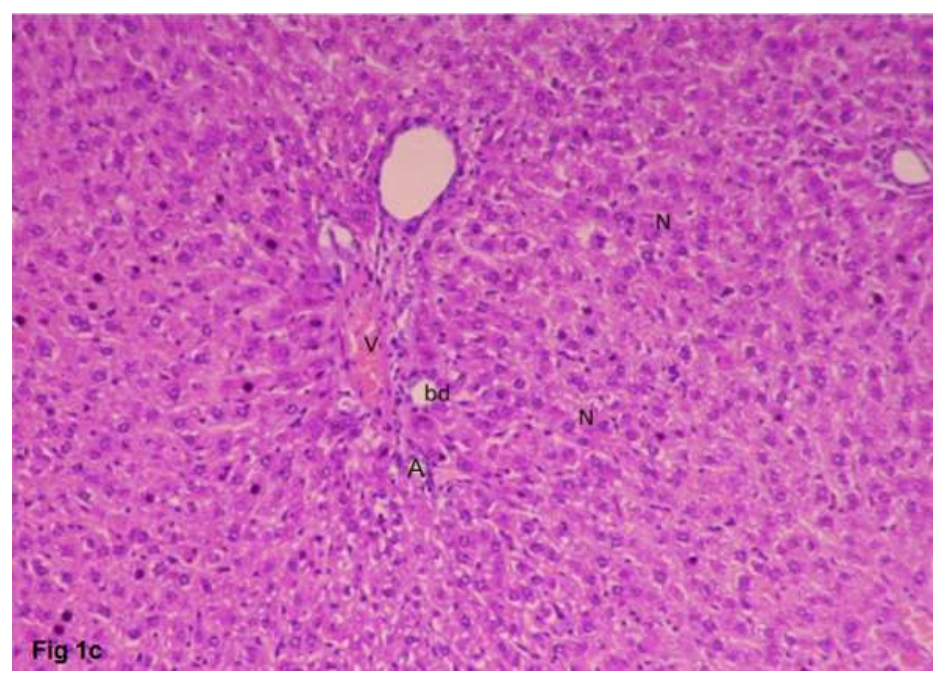

Fig. 1. A photomicrograph of rat liver of group I (control), Fig 1a: showing the classical hepatic architecture. Hepatocytes are arranged in cords radiating from the central vein $(C V)$ and separated by blood sinusoids. portal tract (PT). Fig 1b: showing hepatocytes polyhydral in shape with slightly vacuolated granular acidophilic cytoplasm and vesicular nuclei $(N)$. Blood sinusoids $(\uparrow)$ separating the hepatic cords are seen lined by endothelial cells $(\Delta)$ and kupffer cells $(\mathbf{\Lambda})$ binucleated hepatocytes are also seen(blue arrows). Fig 1c: showing portal tract (PT) with its structures; branches of portal vein (v), hepatic artery (A) and bile duct (bd). (H\&E stain, Mic. Mag. Figla $\times 100-$ Figlb $\times 400-$ Figlc $\times 200)$. 

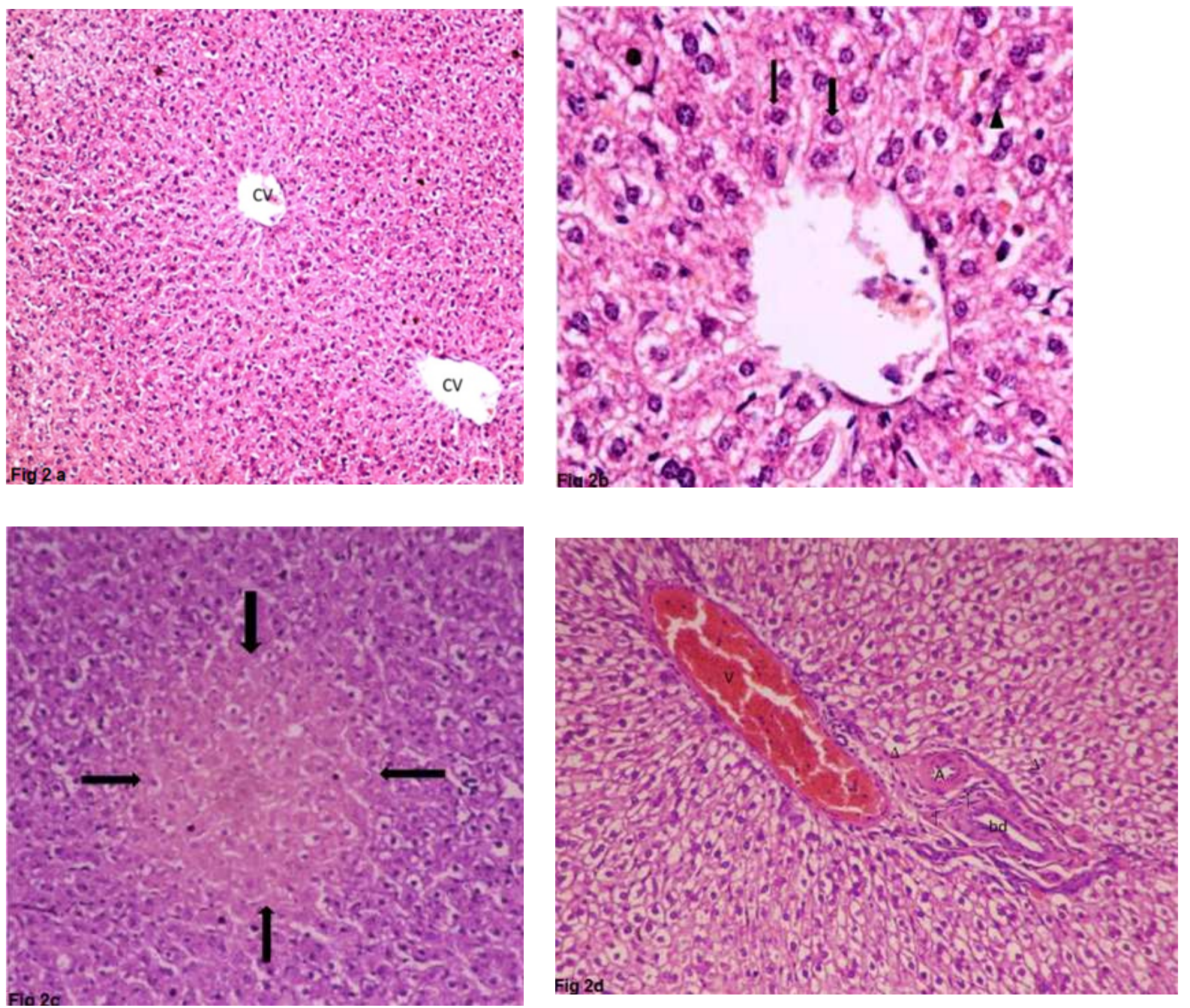

Fig. 2. A photomicrograph of rat liver of group II. Fig 2a: showing mild affection of the hepatic lobule with preserved hepatic architecture. Hepatocytes arranged in cords radiating from central vein (CV) and separated by blood sinusoids. Fig 2b: Hepatocytes are polyhydral in shape. Some hepatocytes appear

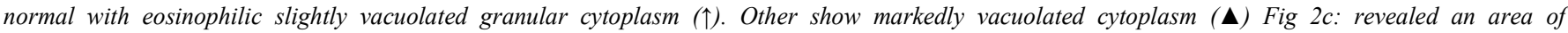
hypereosinophilia of hepatocytes ( $\uparrow)$. Fig $2 d$ : Some of hepatocytes exhibit vacuolated cytoplasm ( $\Delta$ ). Mononuclear cellular infiltration ( $\uparrow)$ is seen in the portal tract. Branch of hepatic artery (A), branch of portal vein (V) and branch of bile duct (bd). (H\&E stain, Mic. Mag. Fig $2 a \times 100-F i g 2 b \times 400-$ Fig2c $\times 200$ Fig $2 d \times 200$ ).
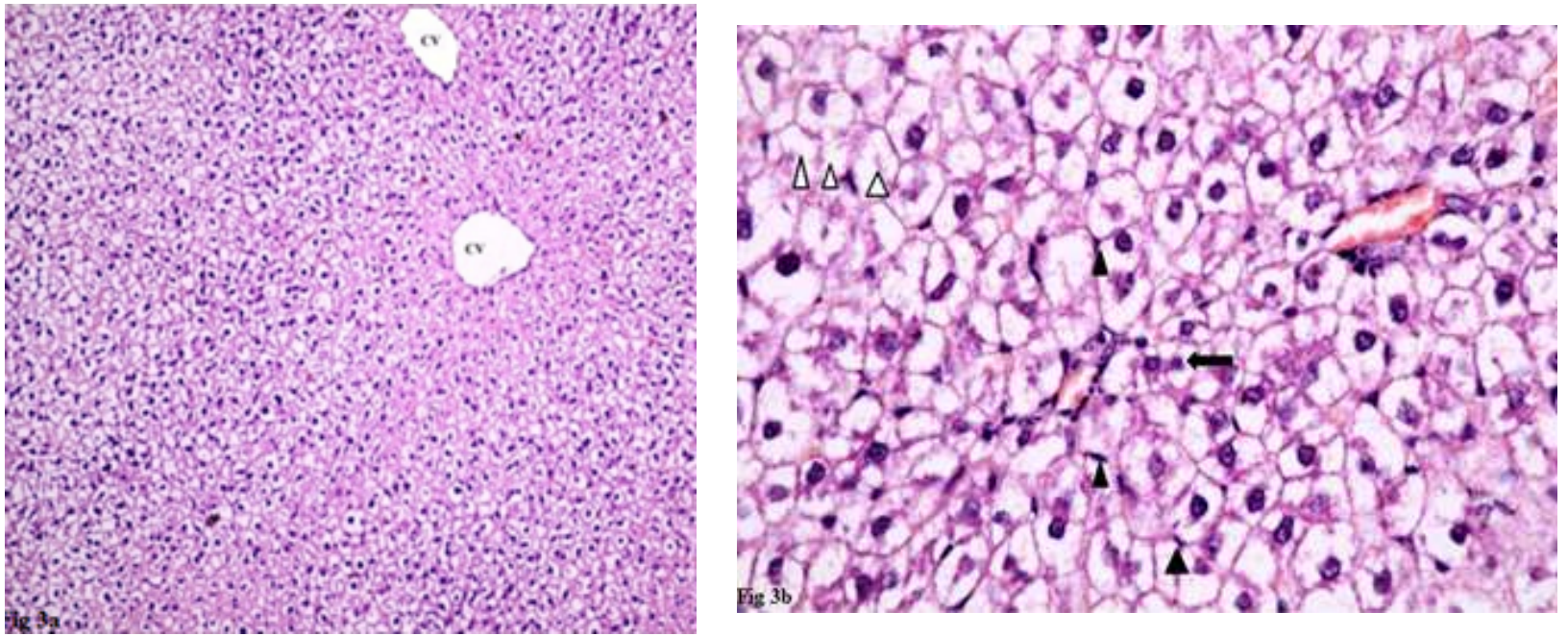


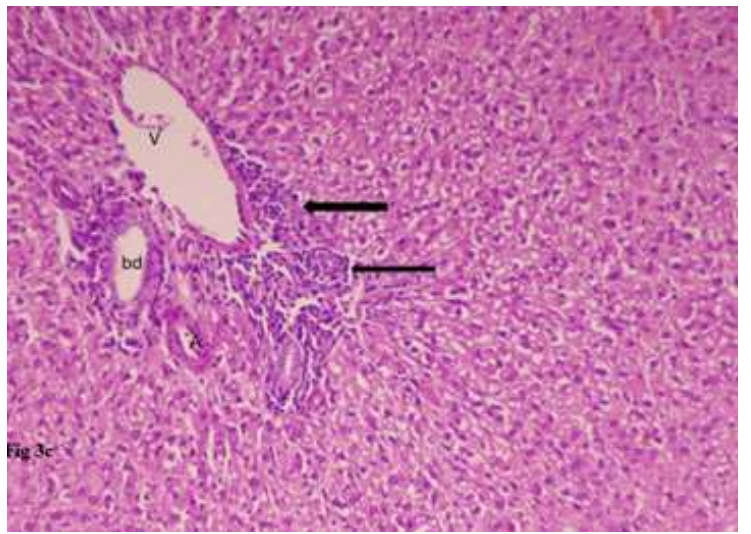

Fig. 3. A photomicrograph of rat liver of group III. Fig 3a: showing marked affection of the hepatic lobules with disorganization of hepatic architecture. The blood sinusoids are obliterated. Hepatocytes appear swollen and vacuolated. Congested central vein (CV). Fig 3b: showing markedly vacuolated and swollen hepatocytes with obliteration or narrowing of blood sinusoids in between. Some cells show dark eccentric nuclei ( $\uparrow$ ), others appear with karyolytic nuclei (4). Prominent nuclei of Kuppfer cells are observed (\). Fig 3c: showing extensive swollen hepatocytes around the portal triad. The portal tract exhibit congestion of portal vein (V). Hepatic artery (A), bile duct (bd). (H\&E stain, Mic. Mag. Fig3a $\times 100-$ Fig3b $\times 400-$ Fig3c $\times 200)$.

H\&E stained sections of liver of the control group revealed normal characteristic of hepatic architecture; the hepatic lobules appeared to be made up of hepatocytes arranged in cords radiating from the central veins. They were polyhedral in shape with granular acidophilic and slightly vacuolated cytoplasm and rounded vesicular, centrally located nuclei (fig. 1a). In between the hepatic cords, the hepatic sinusoids appeared as narrow spaces lined with flattened endothelial cells and few bulging branching Kupffer cells (fig. 1b). The portal tracts showed the normal appearance with one bile duct radical, branch of hepatic artery and branch of portal vein, all were enclosed in scanty amount of connective tissue (fig.1c). The histological sections of rats of group II revealed more or less preserved hepatic architecture. The hepatocytes are arranged in cords radiating from central veins and separated by blood sinusoids. Some of the hepatocytes appeared with acidophilic slightly vacuolated granular cytoplasm while others showed markedly vacuolated cytoplasm. Hepatocytes with hypereosinophilic cytoplasm were also noticed. Some hepatocytes near the portal tract were vacuolated with dark nuclei. Mononuclear cellular infiltration was seen in the portal tract (fig. 2a, b, c, d). In group III, there was diffuse affection of the hepatic lobule. The hepatic architecture was disorganized with marked affection of the hepatocytes. They showed extensive vacuolation of their cytoplasm, some of their nuclei appeared dark and eccentric, others showed karolytic nucleus. The central vein appeared congested. Most of the blood sinusoids appeared narrow or even obliterated. The portal area revealed congestion of its vessels (fig.3a, b, c).
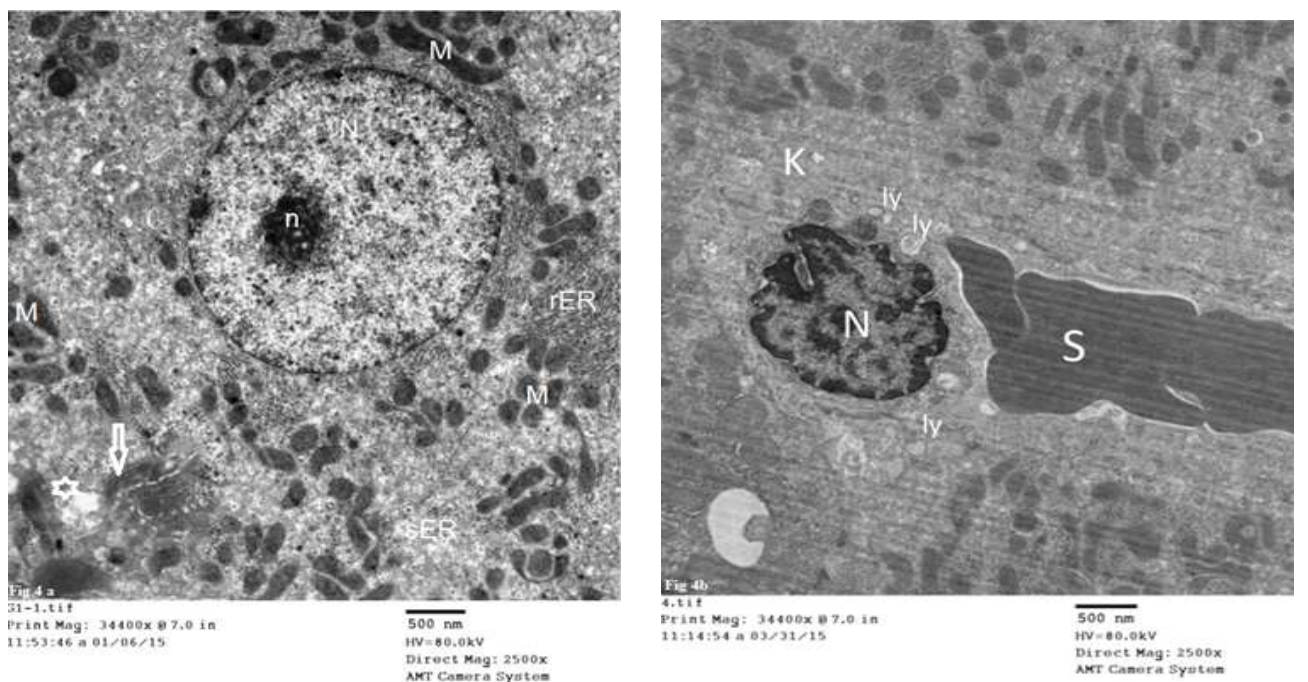

Fig. 4. Electron micrograph of control rat liver (group I) showing Fig 4a: a hepatocyte with euchromatic nucleus (N) of regular outline and prominent nucleolus (n). The cytoplasm contains numerous mitochondria (M), multiple arrays of rough endoplasmic reticulum (rER), vesicles of smooth endoplasmic reticulum (sER). Part of two adjacent hepatocytes enclosing a bile canaliculus with microvilli (*) protruding into its lumen and bounded by desmosomes ( $\uparrow$ ). Fig 4b: showing a Kupffer cell ( $k$ ) lining a blood sinusoid (s). It has a large irregular nucleus (N) and multiple lysosomes (Ly) are noticed in its cytoplasm. (Mic. Mag. × 2500). 

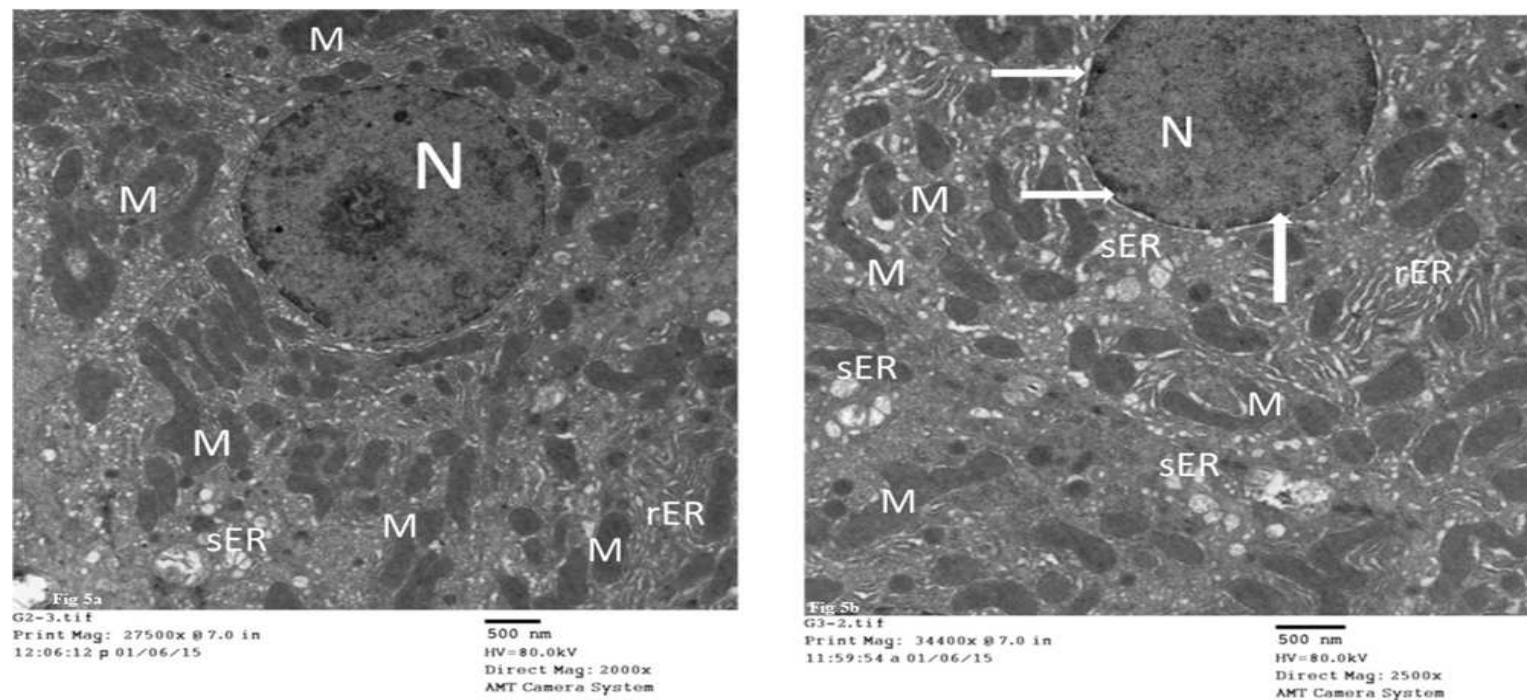

Fig. 5 (a\&b). Electron micrograph of rat liver (group II) showing two adjacent hepatocytes with the cytoplasm containing multiple dilated profiles of smooth endoplasmic reticulum (sER)and rough endoplasmic reticulum $(r E R)$. Multiple pleomorphic mitochondria with dense matrix $(M)$ are seen. The perinuclear cisternae $(\uparrow)$ are also dilated. Nucleus (N). (Mic. Mag. $\times 2000)$.
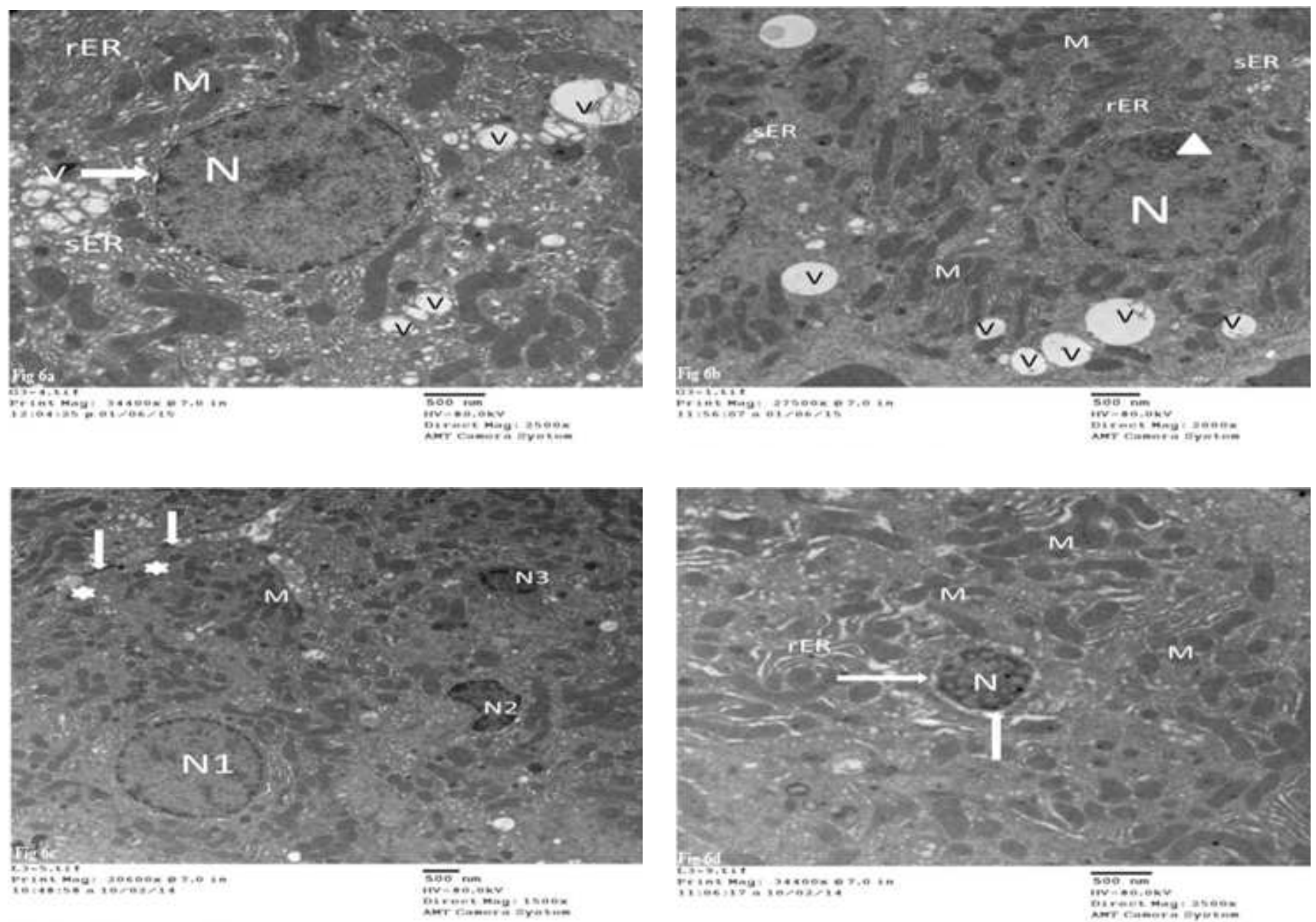

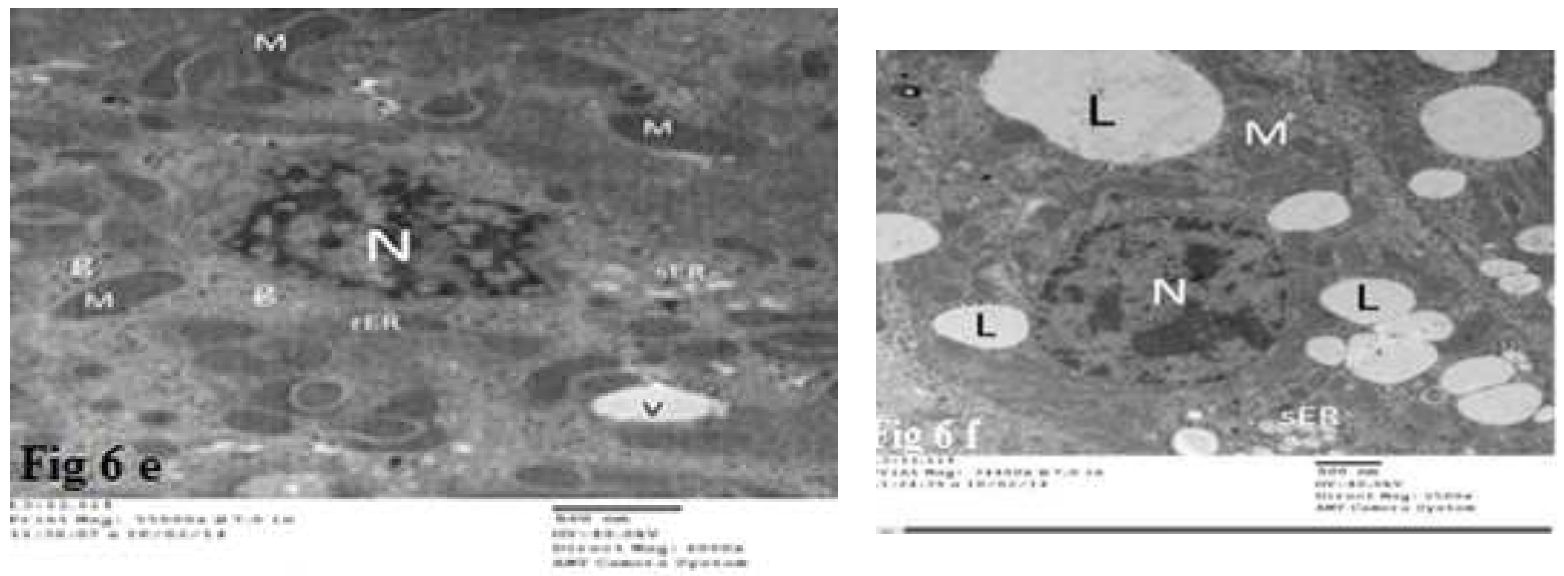

Fig. 6. Electron micrograph of rat liver (group III). Fig 6a: showing a hepatocyte with dilated perinculear cisternea ( $\uparrow$ ), vacuoles (V). Fig 6b: the cytoplasm shows multiple vacuoles $(V)$ of different sizes. Fig 6c: showing multiple adjacent hepatocytes with variable sized and shaped nuclei (N1, N2, N3) tight junction ( $\uparrow$ ) and bile canaliculus (*). Fig 6d: showing a hepatocyte with a dense and small nucleus (N). The nucleus shows vesiculation with dilated perinuclear cisternea ( $\uparrow$ ). Fig 6e: showing a hepatocyte with dense small and irregular nucleus $(N)$ with vesiculation. The cytoplasm contains glycogen granules (g). Fig 6 $f$ : showing multiple lipid droplets (L) occupy most of the cytoplasm. Multiple dilated smooth endoplsmic reticulum (sER). Multiple pleomorphic mitochondria (M) with dense matrix are also seen. Rough endoplasmic reticulum (rER) and nucleus (N). (Mic. Mag. Fig 6a $\times 2500-$ Fig $6 b \times 2000-$ Fig $6 c \times 1500-$ Fig $6 d \times$ 2500- Fig $6 d \times 4000$ - Fig $6 d \times 2500$ ).

The liver of control rats (group I) revealed normal hepatocytes with rounded regular euchromatic nuclei and prominent nucleoli. The cytoplasm of these cells showed numerous rounded to oval mitochondria, multiple parallel arrays of rough endoplasmic reticulum, smooth endoplasmic reticulum, glycogen particles and few lysosomes. Bile canaliculi were seen as narrow spaces limited by short microvilli of two adjacent hepatocytes and bounded by desmosomes. Kupffer cells with irregular nuclei and many lysosomes were seen lining blood sinusoids (Figs. 4a, b). Electron microscopic examination of group II revealed moderate changes of most liver cells. The cytoplasm exhibited pleomorphic mitochondria with dense matrix, dilated rough endoplasmic reticulum and dilated smooth endoplasmic reticulum. The perinuclear cisterna was also dilated (Figs.5a, b). Sections of liver of rats of group III revealed marked changes involving both the cytoplasm and the nucleus. The cytoplasm showed many vacuoles, dilated rough endoplasmic reticulum, dilated smooth endoplasmic reticulum and pleomorphic mitochondria with dense matrix. The nuclei of most of the hepatocytes showed dilated perinuclear cisternae and other showed intranuclear inclusion. Variability in shape and size of nuclei was noticed with vesiculation of their chromatin content. Many Kupffer cells were seen lining the blood sinusoids (Figs. 6 a,b,c,d,e,f).

\section{Discussion}

Lead $(\mathrm{Pb})$ is a heavy soft metal that occurs in nature as oxide or salts, it is one of the most hazardous and cumulative environmental pollutants (Milnes et al., 2006). Once it is absorbed from gastrointestinal tract, lead bounds to erythrocytes and is widely distributed initially to soft tissues such as liver, kidney, brain and spleen (Needleman, 2004). The concentration of lead residues in tissues of animals depend upon the rout of entry and period of exposure to the environmental pollutants (air, water and plants) where inhalation of polluted dust on fumes was more dangerous than oral ingestion of polluted water and plants for long period. Most orally ingested lead is deposited in the skeleton (National Academy of Science, 1972). Initially, lead deposited in bone until a possible threshold is reached then it deposited in other tissues especially the kidneys. The ingested or inhaled lead particles pass to the blood stream and $82 \%$ is excreted in feces and urine. Only $0.5 \%$ is excreted with the milk and the rest (17.95\%) remains and restored in tissues and body organs (Baars et al., 1988). Administration of very high dose of lead to animals results in highest lead accumulation in the kidney then liver, bone marrow, brain and finally in the heart muscles. Whereas, chronic oral administration of low doses of lead results in accumulation particularly in bone marrow, kidney and skeletal muscles in most animal species (Frangenberg,1986). The liver via the portal vein is the first organ exposed to internally absorbed nutrients and other xenobiotics. The liver is composed of highly active metabolic tissue containing huge complement of detoxification machinery system (AlUbaidy et al., 2006).

In the present study, the effect of same dose of lead $(4 \mathrm{mg} / \mathrm{kg}$ body weight) on two groups of adult albino rats named group II and group III for different durations; 2 and 4 weeks respectively was studied. The hair of the rats of group I (control group) was healthy while in group II and III (experimental groups); the hair was brittle, pale and scarce. This could be explained by the effect of lead on protein metabolism including keratin of hair. To our knowledge this is not discussed by other studies.

The effect of lead acetate on body weight gain was assessed in the present study; the final body weight of intoxicated rats with lead was significantly lower than that of 
the healthy normal group. This harmful effect of lead on the body weight gain was elevated paralleled with the increase duration of exposure. The amount of food intake of the three groups was unchanged significantly. This means that the values of food intake were not paralleled to the rate of growth and feed efficiency. The obtained results are in agreement with (Barker, 2002). The decreased body weight gain may be associated with several factors, one of which is imbalanced metabolism produced by impairing zincdependent enzymes which are necessary for many metabolic processes; also lead decreases the level of erythropoietin hormone which has anabolic effect (Sakata et al., 2007).

Decreased body weight was previously observed by Allouche et al., (2011) who administered $0.1 \%$ lead acetate to male rats during 11 months.

In the other hand, Haouas et al., (2014) attributed the decrease in weight gain to malabsorption of nutrients from direct toxic effects of lead on the gastrointestinal tract or by inhibition of protein synthesis.

In the present study, the weight of the liver was significantly increased in group II and III as compared with control group; this is due to reticular cell hyperplasia as a defense mechanism to lead exposure. These results are in accordance with (Ibrahim et al., 2012). This detected elevation in the organs weight was thought to be due to the necrosis and apoptosis which could be attributed to the accumulation of the lipids in the organ (Upasani and Balaraman, 2001). Upasani and Balaraman,( 2001) in their study of the effect of lead, found that $\mathrm{Pb}^{2+}$ treatments produced a significant accumulation of lipids in kidney cells of rats. Valko et al., (2006) attributed the increased weight of liver and other organs to tumorigenicity of lead salts in general, and revealed that lead acetate is carcinogenic in rats and the kidney is the most important and perhaps the target organ.

In the present study, rats exposed to lead acetate showed a significant increase in serum SGOT and SGPT concentrations as compared with the control group, the level of SGOT was increased more significantly than SGPT. The elevated serum levels of transaminases, which are located primarily in the cytosol of hepatocytes, is a sign of damage which leads to liver dysfunction in treated rats. The level of SGOT was increased in both experimental groups as compared to the control one. But it increased more significantly with increased duration of exposure from 2 to 4 weeks. SGPT is present in liver, kidney, heart, skeletal muscles, intestines, and RBC and its increased values is specific indicator of hepatocellular damage. SGOT is present mainly in muscles and increases in its activity related to the leakage of enzyme from muscles because of muscular activity induced by intoxication. Direct effect of lead on muscles increasing the permeability of cell membrane cannot be excluded (Blazovic, 2001). Elevation of both SGPT and SGOT in blood had been used also as an indicator of altered permeability of plasma membrane, cellular damage, and altered metabolism during lead toxicity (Upasani and Balaraman, 2001). Increase SGOT with lead toxicity in the present study was in agreement with the studies done by (Shalan, et al., 2005), (Khan et al., 2008), (Moussa and Bashandy, 2008), (Herman et al., 2009), (Allonche et al., 2011), (Mehana et al., 2012), (Azoz and Raafat, 2012) and (Nabil et al., 2012).

The present study revealed various degrees of histological changes that accompanied the biochemical changes in the liver tissue in experimental groups as compared with those of control group (group I). These changes were duration dependent; the longer the duration the more the damaging effects.

Light microscopic examination of experimental groups revealed disturbed hepatic architecture. Some of the hepatocytes appeared with acidophilic slightly vacuolated granular cytoplasm, others showed markedly vacuolated cytoplasm and others with hypereosinophilic cytoplasm. Mononuclear cellular infiltration was seen in the portal tract. The previous findings are in agreement with Suradkar et al., (2010) and ( Haouas et al., 2014). The hypertrophy was due to the swelling of intracellular organelles especially mitochondria and endoplasmic reticulum (Rosser and Gores, 1995). Apoptotic alteration might be followed by organelles swelling especially the mitochondria, endoplasmic reticulum and rupture of lysosomes which might lead to amorphous eosinophilic cytoplasm as an initial sign in the sequence of hepatocytes necrosis before shrinking and dissolution of nuclei (Pandey et al., 2008). The hepatocytes necrosis due to chronic lead exposure might indicate oxidative stress on these cells by glutathione depletion.

Lymphocytic infiltration and sinusoidal blood congestion after treatment with lead are indicators of liver damage. Similar investigations have also been reported by ((Liu et al, 2001); (Joher et al,. 2004); EL-Sokkary et al., 2005) and (Sharma et al,. 2010 ). The lymphocytic infiltration observed in this study following lead treatment show evidence of cell irritability, inflammation and hypersensitivity to the lead. Cellular infiltration depicted in both group II and III that characterized the role of neutrophils and mononuclear cells in the liver mediated cytotoxicity. In addition, our results showed central vein congestion in accordance with the findings of (El-Sokkary et al., 2005) who administered 100 $\mathrm{mg}$ of lead-acetate to rats.

In the present study; EM examination of sections of liver of group II and III revealed marked changes involving both the cytoplasm and the nucleus. The cytoplasm showed many vacuoles, dilated rough endoplasmic reticulum, dilated smooth endoplasmic reticulum and pleomorphic mitochondria with dense matrix. The nuclei of most of the hepatocytes showed dilated perinuclear cisternae and other showed intranuclear inclusion. Variability in shape and size of nuclei was noticed with vesiculation of their chromatin content. Many Kupffer cells were seen lining the blood sinusoids.

Hepatic toxicity displays itself in the form of cell vacuolation which is a cellular defense mechanism against injurious substances. These substances were segregated in vacuoles and thus prevented from interfering with cellular 
metabolism. It has also been suggested that cytoplasmic vacuolation is mainly a consequence of disturbances in lipid inclusions and fat metabolism (Mollendorf, 1984). This vacuolation might also result from disturbance in the oxidative phosphorylation in the mitochondria with suppression of ATP production and failure of the ATP dependent sodium pump at the cell membrane, resulting in accumulation of sodium intracellularly and consequent entry of water into the different cellular compartments which results in cellular swelling. For several years, a special attention has been paid to oxidative stress; situation of an excessive production of reactive oxygen species (ROS) ( Haouas et al., 2014).

Hepatotoxins, rapidly induces proinflammatory cytokines, such as TNF- $\alpha$ and IL-1 $\beta$ by Kupffer cells, and recruit stromal cells of the liver (endothelial cells, and stellate cells) to participate in this inflammatory response via paracrine production of cytokines as well as chemokines to attract circulating immune cells, further amplifying an inflammatory response (Aykin-Burns, 2003)( Haouas et al., 2014). Chemokine (released by kuppfer cells in liver damage) play an important role in inflammatory responses as mediators of leukocyte maturation, trafficking and activation.

zinc and copper are essential components of antioxidant enzymes of the body that play an important role in the prevention of free radical - induced damage to tissues

(Evans and Halliwel, 2001), in addition zinc protects the peroxidation of membrane lipids, possibly by displacing bound transition metal ions (Bettiger et al., 1980). Patora and Swarup, (2004) recorded that administration of lead significantly decreased zinc and copper concentration in cardiac tissue of calves where it leads to reduction in the absorption of micronutrients from gastrointestinal tract, besides interaction of lead and trace mineral at tissue level.

Considerable alterations induced by lead intoxication were seen in the nuclei of the hepatocytes. This might be due to increased cellular activity and nuclear interruption in the mechanism of lead detoxification. Some of the pleomorphism alterations seen in the present study were in agreement with (Abd El-aal, 1989); (Nehru and Kaushal, 1993); (Jarrar et al., 2006) and (Jarrar and Taib, 2012). Zusman et al., (1991) in their studies indicate that nuclear polymorphism is seen in hepatic dysplasia and carcinomatous lesion. Cell necrosis and vacuolization induced by lead toxicity as shown by the present work were described previously by other studies (Abd El-aal et al., 1989; Nehru and Kaushal, 1993).

The cytoplasmic swelling with hydropic degeneration as seen in the results of the present study might be accompanied by the leakage of lysosomal hydrolytic enzymes that lead to cytoplasmic degeneration and macromolecular crowding (Del Monte, 2005).

The data of the present study showed that lead activates the phagocytic activity of the sinusoidal cells by increasing the number of Kupffer cells. Similar findings were reported by other investigators (Nehru and Kaushal, 1993). This might be a result of increased autophagy throughout the hepatic tissue to help in removing the accumulated lead and its metabolites where lysosomes are involved in the intracellular breakdown into small metabolic products. The produced Kupffer cells hyperplasia might be correlated with the amount of injury to the hepatic tissue induced by lead intoxication and represent a defense mechanism of detoxification and might be contributed to hepatic oxidative stress (Neyrinck, 2004).

In the present study the experimental groups showed disorganized hepatic architecture with marked affection of the hepatocytes due to periportal fibrosis. Liver fibrosis represents the final common pathway of almost all types of chronic liver diseases characterized by excessive connective tissue deposition in extracellular matrix (ECM). ROS can activate fibrogenic gene expression and transforming growth factor (TGF- $\beta 1$ ) signaling pathway, which is known to play major role in the activation of hepatic stellate cells (HSCs) in liver fibrosis (Bartosz, 2008). Hepatic stellate cells are located in the subendothelial (Disse's) space, between the hepatocytes and the anti-luminal side of sinusoidal endothelial cells. HSCs comprise approximately one-third of the non-parenchymal cell population and almost $15 \%$ of the total number of resident cells in normal liver. Experimental data have demonstrated that activation of Kupffer cells (KCs) is a central event in the initiation of liver injury. Moreover, recent evidences indicated a cross-talk between liver macrophage/Kupffer cell and HSCs in the regulation of HSC activation (Bartosz, 2008; Al-Fara, 2010 and Almansour et al., 2009). The activation of Kupffer cells is an important source for induced inflammatory mediators such as TNF- $\alpha$ and IL-1 $\beta$, IL-6, and IL-8, which in turn contribute to generation free radicals in the liver(Ahamed, 2007). In a healthy liver, HSCs are quiescent cells and contain numerous vitamin A lipid droplets, constituting the largest reservoir of vitamin A in the body (Pande, 2002). When the liver is injured due to viral infection or any hepatic toxins, HSCs receive signals secreted by damaged hepatocytes and immune cells, causing them to transdifferentiate from a resting vitamin A-rich cell into active, proliferating, fibrogenic, and contractile cell leading to hepatic fibrosis. Activated HSCs are the key cells implicated in the accumulation of extracellular matrix materials, including type I collagen (Del Monte, 2005). Studies have shown that fibrotic lesion of the liver also typically involves a reduction hepatic storage of total retinol. The vitamin A status of the liver plays an important role in hepatic fibrogenesis. The reduction of retinoid levels in HSC may stimulate the transformation of these cells into fibroblasts and contribute to fibrogenesis (Shinozoka et al, 1996). In addition, it has been demonstrated that activated Kupffer cells, infiltrating monocytes, and damaged hepatocytes are the sources of transforming growth factor (TGF)- $\beta 1$ stimulation, which trigger the initiation of intracellular signaling cascades that lead to the activation of HSCs. and subsequent deposition of type I collagen (Yagminas et al., 1990). 


\section{Conclusion}

Over viewing our results we find that exposure to lead acetate induces chronic inflammation and injury in the liver. The degree of liver cell damage is parallel to the duration of exposure.

\section{References}

[1] Abd El-aal SF, Shalaby SF, Badawy WB, Sammour SA. Effect of lead nitrate administration on liver and kidney structure in rats. J. Egypt Soc. Parasitol. 1989; 19(2):689-99.

[2] Ahamed M and Siddiqui MKJ. Low level lead exposure and oxidative stress current opinions. Clinica Chimica Acta 2007; 383:57-64.

[3] Al-Fara M. Histochemical alterations induced by lead in the liver and kidney of male rats and the protective role of ascorbic acid. Ph.D. Thesis, 2010; Dept. of Zoology, College of Science, King Saud University.

[4] Allouche L, Hamadouche M, Touabti A and Khennouf S. Effect of long term exposure to low or moderate lead concentrations on growth lipid profile and liver function in albino rats. Advances in biological research 2011, 5(6): 339-47.

[5] Almansour M, Al-Otabi N, Alarifi S, Ibrahim S, Jarrar B. Histological and histochemical alterations induced by lead in the liver of the quail Coturnixcoturnix. Toxicol. Environ. Chem. 2009;91(6):1191-203.

[6] Al-Ubaidy B, Al-Khashali DK and Numan NA. The role of oxidative stress in lead poisoning. Iraqi J Pharm Sci 2006; 15(1):70-5.

[7] Arneson W, Brickell J. Assessment of liver function. In: Clinical Chemistry: A Laboratory Perspective. Arneson W.\& Brickell J. (eds.) F.A. Davis Co., Philadelphia, 2007;pp:233- 66.

[8] Aykin-Burns N, Laegeler A, Kellogg, G, Ercal N. Oxidative effects of lead in young and adult fisher 344 rats. Arch. Environ. Contam.Toxicol. 2003; 44:417-20.

[9] Azoz HA and Raafat RM. Effect of lead toxicity on cytogenisity, biochemical constituents and tissue residue with protective role of activated charcoal and casein in male rats. Environ. Australian Journal of Basic and Applied Sciences 2012; 6(7): 497-509.

[10] Baars A J, Spierenburg IJ and Graaf GJ. Chrome lead and cadmium poisoning in farm animals. 2 nd annual conference on trace. Substances in environ. Health1988. St. touis, Missouri 23 -25 May (1988) Edited by Hemophill, D.D

[11] Bahl I, Kaul M and Garg K. Textbook of Histology: Colour Atlas 2014;5.

[12] Barker H. Nutrition and Dietetics for Health Care. 10thed. Churchill Livingstone, Philadelphia, London. 2002:47-57.

[13] Bartosz G. Reactive oxygen species: destroyers or messengers Biochemical Pharmacology 2008; 77(8):1303-15.

[14] Bettiger W J, Reeves P G, Savage J E and O'dell B L. Interaction of zinc and vitamin $\mathrm{E}$ in the chick. Proceedings of the society for experimental Biology and Medicine 1980; 163: $432-6$.
[15] Blazovic A, Abaza M, Sipos P, Szentimihaly K, Feher E, Szilagyi, M. Biochemical and morphological changes in liver and gall bladder bile of broiler chicken exposed to heavy metals (cadmium, lead, mercury). Trace Elem. Electrolyte. 2001; 19:42-7.

[16] Bozzola JJ, Russell LD. Principles and Techniques, Specimen preparation for transmission EM. Boston London: John and Bartlett publishers; 1992: 16- 47.

[17] Carletons HM, Drury RAB, Willington EA, Cameron R. Carleton's histological techniques. $5^{\text {th }}$ ed. Oxford: Oxford University press. $1980 ; 140-222$.

[18] Del Monte U. Swelling of hepatocytes injured by oxidative stress suggests pathological changes related to macromolecular crowding. Med. Hypotheses. 2005;64(4):818-25.

[19] El-Sokkary GH, Abdel-Rahman GH, Kamel ES. Melatonin protects against lead-induced hepatic and renal toxicity in male rats. Toxicology 2005;213: 25-33.

[20] Evans P and Halliwell B. Micronutrients. Oxidant / antioxidant status. British J. Nutr. 2001; 855:57 -74.

[21] Frangenberg J. Pb, Cd, $\mathrm{Fe}$ and $\mathrm{Cu}$ in organen Von Krankten Kalbern Zur erlangung des doctor grades beim fachbereich vetrinar medizin lustus liebig. 1986. Universtate Gie Ben.

[22] Gartner LP and Hiatt JL. Color textbook of histology. Saunders Elsevier 2007; 3.

[23] Glauret AM. Fixation, dehydration and embedding of biological specimens. 6th ed. Amsterdam, New York, Oxford; North Holland Publishers Company; 1986: 123- 176.

[24] Haouas Z, Sallem A, Zidi I, Hichri H, Mzali I and Mehdi M. Hepatotoxic Effects of lead acetate in rats: histopathological and cytotoxic studies. J Cytol Histol 2014;5(5):1-6.

[25] Herman DS, Geraldine $M$ and venkateshT. Influence of minerals on lead - induced alterations in liver function in rats exposed to long term lead exposure J. Hazard Mate. 2009, 166(2-3): 1410-4.

[26] Hernberg S. Lead Poisoning in a Historical Perspective. Am J of Ind Med 2000; 38:244-54.

[27] IARC. Summaries \& evaluations: Inorganic and organic lead compounds. Lyon, International Agency for Research on Cancer. IARC Monographs for the Evaluation of Carcinogenic Risks to Humans 2006; Vol. 87.

[28] Ibrahim NM, Eweis EA, El-Beltagi HS, Abdel-Mobdy YE. Effect of lead acetate toxicity on experimental male albino rat. Asian Pac J Trop Biomed 2012; 2: 41-6.

[29] Jarrar BM and Taib NT. Histological and histochemical alterations in the liver induced by lead chronic toxicity. Saudi J Biol Sci. 2012; 19(2): 203-10.

[30] Jarrar BM, Mahmoud ZN, Al-Enazi M, Taib NT. Histochemical alterations in the activities of hepatic dehydrogenases induced by lead in male albino rats (RattusNorvegicus) Egypt. J. Zool. 2006; 46:217-25.

[31] Jin Xu, Lian L, Chen Wu, Wang X, Wen Fu, Xu J. Lead induces oxidative stress, DNA damage and alteration of $\mathrm{p} 53$, Bax and Bcl-2 expressions in mice. Food and Chemical Toxicology 2008; 46:5; 1488-94. 
[32] Joher D, Roth JC, Bay GH, Walker J N, Kroczak T J, Los M. Inflammatory response, reactive oxygen species, programmed (necrotic-like and apoptotic) cell death and cancer. Rocz. Akad. Med. Bialymst. 2004;49:31-9.

[33] Khan MSH, Mostafa M, Jahan MS, Sayed MA and Hossain MA. Effect of garlic and vitamin B. complex in lead acetate induced toxicities in mice Bangl. J. Vet. Med. 2008, 6(3): 20310 .

[34] Landrigan PJ. The Worldwide Problem of Lead in Petrol. Bulletin of the WHO 2002;80:10.

[35] Liu CM, Ma JQ, Sun YZ. Protective role of puerarin on lead induced alterations of the hepatic glutathione antioxidant system and hyperlipidemia in rats. Food Chem Toxicol 2011; 49: 3119-27.

[36] Mehana EE, Meki AMA and Fazili KM. Ameliorated effects of green tea extract on lead induced liver toxicity in rats. Exp. Toxicol. Pathol. Doi 2012; 64(4): 291-5.

[37] Milnes MR, Bermudes DS, Bryan TA, Edwards TM, Gunderson MP, Larkin TL et al. Contaminant induced feminization and demasculinization of non-mammalian vertebrate male in aquatic environments. Environ. Res. 2006; 100: 3-17.

[38] Mollendorf A. Cytology Cell Physiology, 1973 (3rd ed), Academic Press New York.

[39] Moussa SA and Bashandy SA,. Biophysical and biochemical changes in the blood of rats exposed to lead toxicity. Romanian. J. Biophy2008; 18: 123-33.

[40] Nabil MI, Esam AE, Hossams E and Abdel - Mobdy YE. Effect of lead acetate toxicity on experimental male albino rate. Asian Pacific Journal of Tropical Biomedicine 2012; 41-6.

[41] National Academy of sciences. Lead air borne lead in perspective Committee on biologic effects of atmospheric pollutants. Division of Medical sciences National Academy of sciences1972. Washington Dc.

[42] Needleman H. Lead poisoning. Annual review of medicine 2004; 55: 209-22.

[43] Nehru B, Kaushal S. Alterations in the hepatic enzymes following experimental lead poisoning. Biol. Trace Elem. Res. 1993;38:27-34.

[44] Neyrinck A. Modulation of Kupffer cell activity: physiopathological consequences on hepatic metabolism. Bull. Mem. Acad. R. Med. Belg. 2004;159(5-6):358-66.

[45] Ovalle WK and Nahirney PC. Netter's Essential Histology $2013 ; 2$.

[46] Pande $\mathrm{M}$ and Flora S. Lead induced oxidative damage and its response to combined administration of lipoic acid and succimers in rats. Toxicology 2002; 177:187-96.

[47] Pandey G, Srivastava DN, Madhuri S. A standard hepatotoxic model produced by paracetamol in rat. Toxicol. Int. 2008; 15(1):69-70.

[48] Patora RC and Swarup D. Effect of antioxidant ascorbic acid, 1 - methionine or \& tocopherol alone or along with chelator on cardiac tissue of lead - treated rats. Veterinarhiv 2004, 74(3): 235-44.
[49] Patrick L. Lead toxicity, a review of the literature. Part 1: Exposure, evaluation, and treatment. Alternative medicine review: a journal of clinical therapeutic 2006; 11 (1): 2-22.

[50] PC - STAT. One way analysis of variance procedure. Georgia University 1995.

[51] Pearce JM. Burton's line in lead poisoning. European neurology 2007; 57 (2): 118-9.

[52] Ross MH and Pawlina W. Histology a text and atlas with Correlated Cell and Molecular Biology. 2010; 6.

[53] Rosser BG, Gores GJ. Liver cell necrosis: cellular mechanisms and clinical implications. Gastroenterology 1995; 108: 252-75.

[54] Sakata S, Shimizu S, Ogoshi K, Hirai K, Ohno Y, Kishi T et al Inverse relationship between serum erythropoietin and blood lead concentrations in Kathmandu tricycle taxi drivers. Int Arch Occup Environ Health. 2007; 80(4):342-45.

[55] Shalan MG, Mostafa MS, Hassouna MM, Hassab El - Nabi SE and El - Rafaie A. Amelioration of lead toxicity on rat liver with vitamin $\mathrm{C}$ and silymarin supplements. Toxicology 2005; 206: 1-25.

[56] Sharma A, Sharma V, Kansal L. Amelioration of lead-induced hepatotoxicity by Allium sativum extracts in Swiss albino mice. Libyan J Med 2010;5:5

[57] Shinozoka H, Ohmura T, Katyal S, Zedda A, LeddaColumbano G, Columbano A. Possible roles of nonparenchymal cells in hepatocyte. Proliferation induced by lead nitrate and by tumor necrosis factor alpha. Hepatology. 1996;23(8):1572-7.

[58] Siest G, Schielef HJ. Interpretation des examen de laboratorie. Karger Ed 1981; 2: 206-23.

[59] Siposet P, Szentmihályi K, Fehér E, Abaza M, Szilyági M and Blázovics A. Some effects of lead contamination on liver and gall bladder bile. Acta Biol Szeged 2003; 47(1-4):139-42.

[60] Stevens A and Lowe J. human histology 2004;3.

[61] Suradkar SG, Vihol PD, Patel JH, Ghodasara DJ, Joshi BP. Patho-morphological changes in tissues of wistar rats by exposure of lead acetate. Veter World 2010; 3: 82-4.

[62] Trevor G, Graham R. Electron Microscopy 2: Practical procedures. In: Bancroft JD, Stevens A (ed). Theory and Practice of Histological Techniques. $4^{\text {th }}$ ed. New York, Edinburgh, London: Chirchill Livingstone. 1996: 585- 626.

[63] Tso P and McGill J. The Physiology of the Liver 2005; 5.

[64] Upasani C, Balaraman R. Effect of vitamin E, vitamin C and spirulina on levels of membrane bound enzymes and lipids in some organs of rats exposed to lead. Indian J Pharmacol. 2001; $33: 185-91$.

[65] Valko M, Rhodes CJ, Moncol J, Izakovic M and Mazur M. Free radicals, metals and antioxidants in oxidative stressinduced cancer. Chemico-Biological Interactions 2006; 160:1.40.

[66] Verity AM. Comparative observations on inorganic and organic lead neurotoxicity. Environmental health perspectives 1990; 89:43-8.

[67] Williams L \& Wilkins. DiFiore's Atlas of Histology with Functional Correlations 2008; 11. 
[68] Xu J, Yan HC, Yang B, Tong LS, Zou YX and Tian Y. Effects of lead exposure on hippocampal metabotropic glutamate receptor subtype 3 and 7 in developmental rats. Journal of negative results in biomedicine 2009; 8: 5 .

[69] Yagminas AP, Franklin CA, Villenenve DC, Glman AP, Little $\mathrm{PB}$, Valli VC. Subchronic oral toxicity of triethyl lead in the male weanling rats: clinical, biochemical, hematological and histopathological effects. Fundam. Appl. Toxicol. 1990;15:580-96.
[70] Young B, Lowe JS, Stevens A and Heath JW. Wheater's functional histology a text and colour atlas 2006;5.

[71] Zusman I, Kozlenko M, Zimber A. Nuclear polymorphism and nuclear size in precarcinomatous and carcinomatous lesions in rat colon and liver. Cytometry. 1991;12(4):302-7. 